\title{
Sociogénesis del feminismo liberal: el feminismo utilitarista
}

\author{
Social genesis of liberal feminism: utilitarian feminism
}

DIEGO DELGADO PASTOR*

\begin{abstract}
Resumen: La historia del movimiento feminista ha sido estudiada con desigual interés. Los estudios sobre la primera ola se han visto reducidos a lo anecdótico de la vindicación de los derechos de la mujer. Esta reducción justifica los conceptos fundamentales de las diferentes obras de la época proponiendo una imagen inocente de las primeras movilizaciones feministas, sujeta todavía al curso mayor de las revoluciones liberales burguesas. Abordar esta primera etapa desde la sociología de sus filosofías y del movimiento social que supuso ya a principios del siglo XIX, es tarea necesaria para consolidar una imagen más real de la complejidad de la organización feminista en sus orígenes. Sólo así podremos hacernos una idea consecuente con la complejidad de sus propuestas.

Palabras Clave: Historia del feminismo, sociología de los movimientos sociales, Utilitarismo, primera ola, filosofía.
\end{abstract}

\begin{abstract}
The history of the feminist movement hasn't been always studied with the same interest. Studies about the first-wave have been reduced to an anecdotic vindication of women rights. This reduction justifies the fundamental concepts of the different works during this period, proposing an innocent image of the early feminist mobilizations, which was still attached to the greater course of the bourgeois liberal revolutions. Tackle this first phase from its philosophical sociology and the social movement it created at the beginning of the XIX century, it is a necessary task in order to consolidate a more real image of the complexity of this feminist organization in its early days. It is the only way to get a consequent idea of the complexity of these proposals.

Keywords: History of feminism, sociology of social movements, Utilitarism, first-wave, philosophy.
\end{abstract}

La vindicación de los derechos de las mujeres suele estudiarse como un fenómeno secundario, una consecuencia indirecta de aquellas transformaciones liberales que fueron fundamentales para comprender nuestra era actual. Cabría pensar que, efectivamente, en el marco más amplio de las transformaciones sociales de la época, la Ilustración supone una nueva era en la apreciación de la libertad de los individuos, fundamentalmente de los individuos varones. El movimiento Ilustrado proyectó la gran transformación social que fue la salida de la minoría de edad hasta entonces asumida, gracias a la cual las mujeres tuvieron la oportunidad de vindicar su espacio.

Fecha de recepción: 09/06/2016. Fecha de aceptación: 25/07/2016.

* Profesor de Enseñanza Secundaria. Correo electrónico: ddelgado11@hotmail.com. Doctorando en la Univ. De Cádiz, línea de investigación en estudios sobre biopolítica en los saberes "psy” (España, 1900-1940), director de tesis, Francisco Vázquez García. 
Esto lleva a varias complicaciones. En primer lugar partimos de un anacronismo que desvincula la labor de las mujeres de la época en el proyecto general revolucionario. Como veremos las mujeres tuvieron un papel activo intelectual y socialmente, enfocado desde un principio en la problemática feminista y bajo la cobertura de una organización social tan consolidada o más que los grupos masculinos. Es importante hacer notar que un movimiento social tan importante como este primer feminismo no se pudo asentar intelectualmente si con anterioridad no hubo un desarrollo firme de las condiciones materiales necesarias para su posterior éxito.

La compleja estructura social que respaldó la visión feminista del espacio social venía ya de lejos. A finales del siglo XVIII hasta principios del XIX proliferan una red de centros donde tienen lugar interpretaciones libres de los comportamientos sociales, prácticas todavía ocultas en el ámbito público pero nuevas y diferentes en torno a los roles sociales de género en lo privado. Estos espacios de sociabilidad son fundamentalmente dos, las tertulias y los salones. Gracias a la labor de las mujeres los salones y las tertulias se hacen cada vez más comunes, las tertulias pasan a constituirse en círculos privados: irrumpe internacionalmente una sociedad paralela en la que ni los comportamientos sexuales, ni los comportamientos morales pueden seguir obedeciendo a los esquemas de lo viejo o lo antiguo. Esto propiciará espacios propios para repensar los cuerpos bajo una nueva medida dentro del universo de los nuevos comportamientos sociales. Lo que empezó como un juego clandestino en muchas ocasiones vino a reestructurar el tipo de sujeción de las mujeres al canon público heteronormativo hegemónico en Europa y a crear nuevos capitales simbólicos que van a fomentar el abandono de estas viejas costumbres.

Los salones tienen su origen "en la famosa chambre bleue del Hotel de Rambuillet de la Francia del siglo XVII cuando se quiere concretar la aparición de una nueva forma de sociabilidad (...) fue en este mismo salón donde nació el movimiento de las preciosas, aquellas salonières que rechazaban todo amor físico a cambio de poder dedicar toda su energía al cultivo del espíritu" (Pérez Cantó y Mo Romero, 2005). Las intelectuales y "activistas" de la época ya mostraron el valor (en algunas ocasiones a altos precios personales) para subvertir el orden del capital sexual en las interacciones simbólicas y corporales. Pudieron liberarse en estos espacios de la condición naturalizada y esencializada de su corporalidad para reflexionar abstracta y libremente bajo nuevas fórmulas de esa idea instaurada en la época de la corporalidad femenina. De hecho actitudes como las de Rousseau o Kant, manifiestamente contrarias a este primer movimiento, suponen una reacción a los logros de la causa feminista.

Estas tendencias se consolidan en el siglo XIX y los salones de las primeras preciosas de la "chambre bleue" son famosos internacionalmente. En Inglaterra, como veremos, se importa esta idea de las preciosistas en Francia y se adapta a la mentalidad de la zona. Estas organizaciones acaban transformándose en organizaciones más complejas como las Hermandades o Sociedades de mujeres que se convertirán en centros de investigación económica, sociopolítica y moral. En el caso de las blue-stocking inglesas los salones se convertirán en centros de debates afables pero no por ello menos importantes, sobre todo porque a estos salones acudirán los que serán los principales políticos, filósofos o juristas que diseñarán las nuevas Constituciones tras las revoluciones burguesas. Estos tendrán la oportunidad de confluir y aprender de las nuevas tendencias de análisis de 
lo social promovida por la intelectualidad feminista de la época (como veremos más adelante esto ocurrirá singularmente en el caso de J. S. Mill y el feminismo utilitarista).

Esta consolidación de los salones (Valcárcel, 1997), como territorio donde las primeras feministas pudieron poner en práctica los nuevos modus operandis que la sociedad moderna les permitía, abrirá un espacio nuevo donde poder actualizar la finalidad de las instituciones: el cambio de paradigma intelectual de la Modernidad produce una cantidad de círculos autoconscientes "con un programa y publican un manifiesto. Constituyen el núcleo material de los movimientos intelectuales y las organizaciones de movimientos sociales de la Modernidad" (Collins, 2005). Desde el Círculo de Mersenne en el XVII hasta la Birmingham Lunar Society, ya avanzado el XIX, junto a estos círculos oficiales de las redes intelectuales y sus representantes (Collins menciona a quince como los más influyentes en la vida intelectual europea), "existían una gran cantidad de salones y grupos de discusión que inundaron la sociedad Moderna y liberal y que luego se acabarían institucionalizando dado su éxito social" (ibídem). Por tanto se trata de una subversión ideada de los rituales de interacción en torno al género público que, al menos de forma horizontal en principio, producen diferentes redes paralelas que van a producir nuevas formas de comunicación gracias al carácter híbrido de éstas (artes y ciencias se combinan).

En la Francia de mediados del siglo XVIII el círculo de los enciclopedistas permite a Sophie de Grouchy, marquesa de Condorcet, introducir las tesis utilitaristas y liberales en una reflexión en su obra Carta sobre la simpatía donde "elabora una teoría del cuerpo en estrecha relación con su propuesta sobre la simpatía" (Hurtado, 2010). No tenemos lugar aquí pero sería muy interesante analizar cómo intelectuales como la marquesa de Condorcet y otras toman de la tradición de la filosofía práctica empirista términos como el de simpatía y los transforman en otro elemento de un nuevo orden discursivo que junto con la utilidad y el placer, aluden directamente a esta subversión de los regímenes de género de la época.

En Inglaterra, a parte de la oficial Birmingham Lunar Society -en conexión con los círculos franceses-, prestaremos especial atención a "los Philosophical Radicals, seguidores de Bentham, entre los que se encontraban Mill y Ricardo. Institucionalmente, controlaban la Encyclopedia Brittanica, y fundaron la Westminster Review y la Universidad de Londres, la primera deslocalización en siglos del monopolio Oxford-Cambridge" (Collins, 2005:532). En el caso español merece especial atención el libro recién publicado por Juan Francisco Fuentes y Pilar Garí, Amazonas de la libertad. Mujeres liberales contra Fernando VII donde podemos situar la herencia de una Ilustración femenina que hallaría en las tertulias gaditanas su mejor expresión, como la de Margarita López de Morla en la que coincidía lo más granado del partido liberal, o la residencia de Cádiz de los Marqueses de Astorga, que era uno de los centros más activos del liberalismo. Cabe constatar también la creación en 1822 de la Junta Patriótica de Señoras de Madrid y, del mismo año, la Tertulia patriótica de Lacy en Barcelona. En Madrid también aparece uno de los salones más importantes del país, regido por la Condesa de Lemos que con la:

Junta de Damas de la Real Sociedad Económica Matritense, la condesa elaboró un informe sobre La educación moral de la mujer que trataba de reformular el modelo tradicional. A través de las Actas de la Junta de Damas se puede seguir su trayectoria en esta institución: dirigió la escuela patriótica de San Martín, se ocupó de la reforma 
de las cárceles de mujeres (...) La actividad intelectual y pública de la condesa no se agotaba en su papel de anfitriona de uno de los salones más célebres, sino que formó parte del primer grupo de socias de la Junta de Damas de la Real Sociedad Económica Matritense y desde ella mostró su utilidad a la patria, sin dejar de ser, a su vez, una excelente administradora de sus propiedades. En su Epistolario ha dejado cumplida cuenta de su actividad como administradora de sus territorios y bienes (Pérez y Mo, op. Cit.).

El caso español es un ejemplo claro de cómo estas sociedades fueron calando en su cultura hasta que la campaña monárquica arrambló con cualquier conato de feminismo en el país: lamentablemente triste fue el caso de la ejecución de Mariana Pineda pero fueron muchas las que sufrieron la "represión ejemplarizante" del gobierno de Fernando VII ansioso de acabar con cualquier atisbo de liberalismo femenino" (Fuentes y Garí, op. Cit., p. 280-81). Estas redes oficiales y alternativas permitieron la publicación de textos filosóficos y políticos a muchas de las intelectuales que se encontraban implicadas en la elaboración de la Reforma Social Ilustrada. Impulsaron además la creación de empresas editoriales asociadas a estos círculos que ampliarán su alcance a la población estudiantil de los nuevos centros universitarios, cuya sociedad más importante en Inglaterra "fue "los Apóstoles" de Cambridge, sociedad que tuvo como miembros entre otros a Whitehead, Russell, Keynes, Moore o Wittgenstein, muchos de los cuales tenían conexión con el círculo literario de Bloomsbury, centrado en torno a Virginia Woolf y la editorial de su marido" (Collins, op. Cit.).

En este ambiente intelectual en Inglaterra se sitúa la polémica que queremos analizar. En la publicación del primer tomo de la Enciclopedia Brittanica, James Mill hace del Gran Principio de Utilidad, ya expuesto en la obra de Bentham, su modelo de gobierno liberal en un artículo denominado Sobre el Gobierno. Si el sentimiento de simpatía ha encontrado siempre un lugar destacado en la filosofía moral anglosajona, no menos importante es la tendencia que sitúa al egoísmo -sentimiento por el cual el individuo está directa y espontáneamente interesado en su propio bienestar y no en el de los demás- como dato clave de la naturaleza humana. Por supuesto, para esta versión del utilitarismo no existe nada parecido a una fusión de intereses, pero sí es posible lograr una identificación entre el interés individual y el interés general. La propuesta que hace J. Mill es una propuesta de corte naturalista e individualista: la teoría de la identificación natural de intereses supone que cada individuo, persiguiendo única y exclusivamente su propio interés, coopera simultáneamente con el interés y la felicidad generales.

En esta interpretación clásica del principio de utilidad descansa toda la teoría de la economía del siglo XVII -como ocurre en la mano invisible de Adam Smith- y su expresión más sintética, recogida en la conocida fórmula de Mandeville, según la cual "los vicios privados propician beneficios públicos", de tradición fisiócrata.

Una variante de esta teoría es la defendida con menos éxito por Hartley y Priestley, según la cual, la identificación de intereses no tiene por qué darse de forma necesaria en toda sociedad, pero sí aparecer de una forma progresiva y gradual, elaborando así una teoría acerca del progreso indefinido de la humanidad. Esta formulación clásica del principio de utilidad lleva a Mill a afirmar que, la mejor forma de hacer útil al Estado es dándole toda la libertad que la utilidad permita a su gobierno, reduciendo así la incidencia que pueda tener 
sobre la progresión natural a acumular riquezas de sus gobernados. Para que un gobierno de este tipo sea útil sus representados no deben ser inútilmente multiplicados (como en la máxima ockhamista), por lo que en la participación pública del marido o del padreltutor, se encuentran ya representados los intereses de las mujeres, con lo cual no se hace necesaria su participación en la vida política ni tampoco el derecho al voto, que Mill justifica en una formulación un tanto obtusa de la "representación" o de la "dependencia natural":

una cosa está bien clara, que todos los individuos cuyos intereses están indiscutiblemente incluidos en los de otros individuos pueden ser excluidos de los derechos políticos sin inconveniente alguno. Desde esta perspectiva puede considerarse a todos los niños, hasta una cierta edad, cuyos intereses están incluidos en los de sus padres. Y también respecto a las mujeres puede considerarse que los intereses de casi todas ellas están incluidos o bien en los de sus padres o bien en los de sus esposos (Mill, ob. Cit.).

La polémica que surge en torno a este humanismo androcentrista del utilitarismo liberal no es una polémica nueva, y no me refiero al problema del ideario patriarcal de la ciudadanía -esto desafortunadamente era bastante común y aceptado- sino a la tendencia a calificar definitivamente el origen de las prácticas sociales: ¿existe un tendencia individual en la naturaleza del egoísmo personal que pueda beneficiar posteriormente a la comunidad de acuerdo con la idea de Smith o Mandeville, que desemboca en un progreso social?, ¿o son más bien los intereses de una comunidad y de sus componentes un conjunto de prácticas artificiales y normalizadas que obviaría este modelo naturalista de los intereses?

Una polémica esta que se da ya dentro del origen del liberalismo, representada aquí en los primeros utilitaristas y que, salvo los hiatos bélicos mundiales, no librará al pensamiento político hasta nuestros días. Podríamos atrevernos tímidamente a decir que el denominado "Utilitarismo clásico" de corte naturalista (más identificado con las teorías progresivas de Smith, Ricardo o los fisiócratas liberales), tiene corta vida ya que, gracias a la resistencia fundamental de algunos de estos círculos intelectuales, la labor de las feministas utilitaristas y liberales (sobre todo de Anne Wheeler y de Harriet Taylor Smith o M. Wolfstonecraft), dejarán obsoletas dichas tesis del liberalismo naturalista aunque sólo desde un punto de vista intelectual.

Y no sólo por el peso de la demostración argumentativa que estas feministas elaboran sino porque la polémica de esta distinción se remonta a una larga tradición que podría encuadrarse en la escuela medieval escocesa desde Scoto y Ockham hasta Hume y Mill (¿responden los conceptos a realidades materiales o son meros "flatus vocis"?). El valor que quiero destacar aquí de la aportación de las feministas liberales se debe precisamente a la crítica cada vez más empírica de la cuestión de la naturaleza social y de los comportamientos, pues nadie mejor que las mujeres de aquella época pudieron entender las trampas que se escondían tras el concepto natural del interés social, individual, nacional o internacional.

En respuesta a James Mill, Anne Doyle Wheeler (intelectual que regenta un salón en Londres) publica un libro en coautoría con W. Thompson titulado La demanda de la mitad de la raza humana, en línea con el de la Vindicación de Wolfstonecraft, pero bajo el paradigma utilitarista. En esta obra viene a reivindicar un nuevo modelo de participación 
social, de agencia social de las mujeres y del concepto de ciudadana. Thompson y Wheeler reclaman un modelo de participación social basado en una idea del utilitarismo que puede negar la armonía preestablecida entre el interés individual y el público, ya que ni existe ni tiene por qué llegar a existir nunca. ¿Cómo conciliarlos? Propiciando lo que se acuñó como la identificación artificial de los diferentes intereses individuales, rompiendo así con el modelo naturalista del utilitarismo clásico. Hecho este que provocó la irrupción dentro la corriente utilitarista de varias tendencias epistemológicas. En este modelo es al legislador al que le corresponde lograr esta identificación artificial por medio de la creación de leyes e instituciones basadas en el principio de la utilidad: la mayor felicidad del mayor número no puede excluir a la mitad de la población. Para el propio Bentham este es el vital papel del legislador, el de árbitro tanto en la moral como en la política y el derecho.

De las dos versiones del utilitarismo expuestas, ésta última es la que otorga mayor relevancia a la esfera de lo político en la regulación de las relaciones sociales, entendiendo lo político como un verdadero contrato social y de participación soberana. La obra de Thompson y Wheeler aparece como la primera defensa en lengua inglesa de los derechos políticos para las mujeres. Publicada en 1825, emprende una sistemática deslegitimación de la concepción tradicional de la identidad femenina, cuestionando no sólo la existencia de una naturaleza femenina, sino proponiendo una explicación de carácter sociológico a la situación de servidumbre de las mujeres.

Esta polémica radical tuvo una repercusión inmediata en la comprensión del propio utilitarismo que, como corriente del pensamiento se escinde entre utilitarismo clásico o naturalista y el nuevo utilitarismo artificialista, de carácter más social junto con la transformación de los discursos sobre la gubernamentalidad de la época. Wheeler y Thompson adoptaron el principio de Utilidad como principio rector de la reforma social moderna, pero difícilmente un principio abstracto de distribución social pudo funcionar según la comprensión androcéntrica de los primeros utilitaristas pues, como hemos visto, enuncia abiertamente la negación de la subjetividad femenina. Y sin subjetividad, según los autores, no se puede ejercer el derecho de la ciudadanía, de ahí la necesidad imperiosa de todas estas reflexiones feministas por construir un sujeto autónomo que les permita alcanzar la categoría que les estaba siendo negada. Desmitificar la visión canónica de la historiografía de la primera ola del feminismo que clasifica la reflexión femenina como simple push social, como reivindicación espontánea de unas demandas determinadas, ayuda a consolidar esta tesis y a devolver una profundidad robada por el imaginario común de la historia de las Ciencias Sociales.

En el declive de las instituciones estatales del Antiguo Régimen, este margen que brindaba el protagonismo del interés común y las recién reconocidas posibilidades comunitarias por la construcción de los intereses poblacionales (representados ahora también por las demandas feministas), la perspectiva "radical" del liberalismo anglosajón había irrumpido ya desde 1819 como una fuerza social mayoritaria y reformadora (Halévy, 2013). Como sostiene Halévy se produce una sustantivación del epíteto radical y autores como Bentham, J. S. Mill, Wheeler, H. T. Smith, etc., llevan a cabo una crítica al modelo naturalista del utilitarismo por un modelo social más justificado en el cálculo comunitario del interés y la competencia sociales ampliados.

La deriva de esta polémica se resuelve en los utilitaristas radicales en el desarrollo de toda una serie de propuestas amparadas a su vez en los progresos de las nuevas ciencias 
sociales como la economía y la estadística, que tratan de recoger lo mejor posible la opinión de las distintas comunidades o asambleas, para poder analizar a posteriori determinados patrones de interés que por repetición o por participación mayoritaria, pueden producir nuevas reglas para conducir a la sociedad de manera más democrática y complaciente. Un ejemplo clave en la producción social del interés común es la propuesta de J. S. Mill y Harriet Taylor en la que, gracias a la influencia de las propuestas de las feministas -fundamentalmente en las obras La esclavitud femenina y La naturaleza o la Sujeción de la mujer-, llevan a cabo ya un estudio estadístico de cómo la violencia de género afecta de manera negativa a la población femenina (analizando para ello empíricamente casos concretos de procesos de separación en la época) y, por coherencia estadística, al interés común. Para el propio John S. Mill la influencia del feminismo de la época y, concretamente, el de su esposa Harriet cambiaría su concepción de las Ciencias Sociales:

De no haber sido por su especial conocimiento de la naturaleza humana y su comprensión de las influencias morales y sociales, aunque sin duda yo hubiese seguido manteniendo mis ideas sobre el asunto, habría tenido una percepción muy insuficiente del modo en que las consecuencias de la situación de inferioridad de las mujeres se enlazan a todos los males de la sociedad en su estado actual, y con todas las dificultades que entorpecen el progreso del género humano (Mill, 2005).

La transformación social moderna y liberal así descrita correspondería con el camino revolucionario al que alude Foucault cuando describe el concepto anglosajón "radical" que, frente a las posiciones tradicionales del derecho público, la ley aparece ahora como un constructo realizado a partir de la voluntad de los ciudadanos de derecho:

La ley se concibe, por lo tanto, como la expresión de una voluntad, de una voluntad colectiva que manifiesta la parte del derecho que los individuos han aceptado ceder y la parte que pretenden reservarse" (...) "y esto nos lleva a otra distinción también muy importante, y es que, por un lado, vamos a tener una concepción jurídica de la libertad: todo individuo posee originariamente, para sí, cierta libertad de la que cederá o no una parte determinada; y por otro lado, la libertad no se concebirá como el ejercicio de una serie de derechos fundamentales, sino que se la percibirá simplemente como la independencia de los gobernados con respecto a los gobernantes" (Foucault, 2009).

En esta mezcla heterogénea de la diferenciación de intereses y de los mecanismos de intercambio y verificación en cuanto a la relación del valor y el precio de lo social y lo privado, los gobiernos liberales se convierten en "algo que manipula intereses. Los intereses son, en el fondo, el medio por el cual el gobierno puede tener influjo sobre todas esas cosas que para él son los individuos, los actos, las palabras, las riquezas, los recursos, la propiedad, los derechos, etc.") (Foucault, íbidem). El problema es que el decurso de la historia no dará demasiado protagonismo a esta crítica feminista del naciente estado liberal y su modelo de Estado. Pese a que las feministas utilitaristas como Wheeler y, posteriormente, H. T. Smith parecen adelantarse a las consecuencias futuras del liberalismo del laissez faire, y a pesar de que el desarrollo teórico de algunas de estas feministas era previsiblemente más riguroso que las intuiciones evolucionistas de teorías como las malthusianas, como todos sabemos la historia no atendió en nada a dicha crítica hasta pasado mucho tiempo y de manera reduccionista y sesgada. 
Una situación que bien podría redefinirse ante el "peligro" advertido por el radicalismo liberal de las primeras feministas que, antes bien de formular esta tendencia a lo comunitario como base de la libertad individual como una solicitud simplista de proteccionismo estatal, supieron adelantarse al denunciar la mengua del poder estatal en la denuncia de las Poorlaws de mediados del siglo XIX y la reivindicación del Estado del Bienestar, los derechos de la ciudadanía de los negros, etc., que tampoco fueron escuchadas. Una vuelta de la mirada sobre la confluencia de la reflexión femenina sobre la idea de gubernamentalidad ya en el comienzo de la época liberal podría aclarar muchos de los tópicos que se mantienen en nuestras sociedades globales, donde a través de la mirada sociológica del modus operandi de los primeros feminismos del siglo XVIII, en la constitución de ese modus operandi, nos encontraríamos con algunas sorpresas en la consideración de un modelo del interés social más allá de las prácticas patriarcales que han consolidado un modelo del interés puramente androcentrista y reduccionista. La cuestión de crear un corpus feminista era precisamente la de descapitalizar todo ese cálculo de la libertad individual no en una imagen esencializada de la noción de riqueza propia del patriarcado sino de recapitalizarla en el único medio donde tendría algún sentido, donde podría surgir algún interés al menos para el liberalismo utilitarista de éstas, en el interés de la comunidad y en el desarrollo del aspecto comunitario e igualitario de las sociedades.

\section{Bibliografía}

Bentham, Jeremy, James, M., Blamires, C. P., \& Pease-Watkin, C. (1999): Political tactics, Clarendon Press, Oxford.

Collins, Randall (2005): Sociología de las filosofías: una teoría global del cambio intelectual, Hacer, Barcelona.

Engels, Federico. (1975): Del socialismo utópico al socialismo científico, Anteo, Buenos Aires.

Foucault, Michel. (2009): Nacimiento de la biopolítica: curso del Collège de France (19781979), Akal, Madrid.

Fuentes, Juan Francisco, y GARÍ, Pilar (2014): Amazonas de la libertad. Mujeres liberales contra Fernando VII. Revista de Estudios Políticos, pp. 166.

Halévy, Élie (1904): La formation du radicalisme philosophique: Le radicalisme philosophique, Vol. 3, Alcan, París.

Pérez Cantó, Pilar; Mo Romero, Esperanza (2005): Las mujeres en los espacios ilustrados. Signos Históricos, enero-junio, pp. 43-69.

Simó, Ricardo Hurtado (2012): Cuerpo y simpatía en la filosofía de Sophie de Grouchy, THÉMATA, Revista de Filosofía, número 46.

Stuart Mill, John (2005): Sobre la libertad, Edaf, Madrid.

Stuart Mill, John (1998): La naturaleza, Alianza Editorial, Madrid.

Thompson, Williams., Wheeler, Anne Doyle (2001): La demanda de la mitad de la raza humana, las mujeres, Comares, Granada.

Valcárcel, Amelia (2004): La política de las mujeres, Cátedra, Madrid.

Wollstonecraft, Mary (2005): Vindicación de los derechos de la mujer, AKAL, Madrid. 